\title{
Mixed Replenishment Policy for ATO Supply Chain Based on Hybrid Genetic Simulated Annealing Algorithm
}

\author{
Hui Huang, ${ }^{1}$ Yan Jin, ${ }^{2}$ Bo Huang, ${ }^{1}$ and Han-Guang Qiu ${ }^{2}$ \\ ${ }^{1}$ School of Economics and Business Administration, Chongqing University, Chongqing 400044, China \\ ${ }^{2}$ School of Computer Science and Information Technology, University of Nottingham, Jubilee Campus, Wollaton Road, \\ Nottingham NG8 1BB, UK \\ Correspondence should be addressed to Bo Huang; huangbo@cqu.edu.cn
}

Received 22 December 2013; Revised 23 February 2014; Accepted 24 February 2014; Published 27 March 2014

Academic Editor: Erik Cuevas

Copyright (c) 2014 Hui Huang et al. This is an open access article distributed under the Creative Commons Attribution License, which permits unrestricted use, distribution, and reproduction in any medium, provided the original work is properly cited.

\begin{abstract}
Timely components replenishment is the key to ATO (assemble-to-order) supply chain operating successfully. We developed a production and replenishment model of ATO supply chain, where the ATO manufacturer adopts both JIT and $(Q, r)$ replenishment mode simultaneously to replenish components. The ATO manufacturer's mixed replenishment policy and component suppliers' production policies are studied. Furthermore, combining the rapid global searching ability of genetic algorithm and the local searching ability of simulated annealing algorithm, a hybrid genetic simulated annealing algorithm (HGSAA) is proposed to search for the optimal solution of the model. An experiment is given to illustrate the rapid convergence of the HGSAA and the good quality of optimal mixed replenishment policy obtained by the HGSAA. Finally, by comparing the HGSAA with GA, it is proved that the HGSAA is a more effective and reliable algorithm than GA for solving the optimization problem of mixed replenishment policy for ATO supply chain.
\end{abstract}

\section{Introduction}

ATO (assemble-to-order) has become one of the most popular production modes adopted by manufacturing enterprises due to its ability of rapidly responding to customers' diversified and personalized demands at a low cost [1]. Under ATO mode, an ATO manufacturer just owns components inventory rather than an inventory of final finished products. Therefore, timely components replenishment is the key to ATO (assemble-to-order) supply chain operating successfully. There are two main component replenishment modes, $(Q, r)$ and JIT. $(Q, r)$ mode has little request on supplier's supply capacity but causes a higher inventory and holding cost [2]. JIT mode lowers the manufacturer's inventory and the probability of components being out of stock but has a high demand on supplier's supply capacity. In addition, it may raise the manufacturer's replenishment cost and total cost due to the increase in the number of replenishment times [3]. Therefore, a manufacturer should adopt different replenishment modes for different components.
There have been numerous researches on the $(Q, r)$ and JIT replenishment policies. Harris is the earliest person who developed Economic Order Quantity model of $(Q, r)$ mode [4]. Tersine and Wacker [5] proposed an $(Q, r)$ inventory model under stochastic demand. Akçay and $\mathrm{Xu}$ formulated a two-stage stochastic integer program which is able to determine the optimal base-stock policy and the optimal component allocation policy for the ATO system [6]. Lu and Song studied a multi-item stochastic inventory system in which customers may order different but possibly overlapping subsets of items, such as a multiproduct assembleto-order system, in order to determine the right base-stock level for each item and to identify the key driving factors [7]. Benjaafar and Elhafsi studied the optimal production and inventory control of an assemble-to-order system with $m$ components, one end-product, and $n$ customer classes [8]. Yang and Pan presented an integrated inventory model to minimize the sum of ordering/setup cost, holding cost, quality improvement investment and crashing cost by simultaneously optimizing the order quantity, lead time, process 
quality, and number of deliveries while the probability distribution of the lead time demand is normal [9]. Wu and Low suggested that the advantages of JIT purchasing may have been overstated in theory and developed the JIT purchasing threshold value (JPTV) models, which overcomes two limitations of the existing EOQCJIT cost indifference point models [10].

However, the manufacturers in these researches only adopt either $(Q, r)$ or JIT to replenish components, which runs counter to the fact that most ATO manufacturers adopt both $(Q, r)$ and JIT modes to replenish components [11]. Betts and Johnston developed a tractable solution method for the decision problem of multiproduct manufacturing scenario under stochastic demand. They revealed several other ways in which JIT replenishment and component substitution can improve performance by limiting the cost of dealing with uncertainty [12]. In their research, they assumed that the manufacturer only replenishes one component by JIT. However, in reality, the manufacturer will replenish several components among all its $n$ kinds of components by JIT. Therefore, the complexity of the mixed replenishment policy for ATO supply chain is $2^{n}$. In automobile manufacturing industry, which is a typical ATO industry, the kind of components of a car is over 20,000. The complexity of replenishment policy for an automobile manufacturer can reach as high as $2^{20000}$. Therefore, to make the mixed replenishment policy for an ATO supply chain not only needs to propose optimization models, but also to design an effective optimization algorithm to search for the optimal solution of the model.

One of the most popular algorithms for combinatorial optimization problem is genetic algorithm (GA), which has the ability of rapid global searching. Therefore, it is widely applied to production management and logistics management, such as production scheduling and path arrangement $[13,14]$. Jalilvand-Nejad and Fattahi studied a flexible job shop scheduling problem with cyclic jobs, in which jobs must be delivered in determined batch sizes with definite time intervals. They proposed a genetic algorithm for the problem and proved its effectiveness [15]. Tasan and Gen proposed a genetic algorithm based approach to the vehicle routing problem with simultaneous pickup and deliveries and proved its performance [16]. Although GA has the ability of rapid global searching, it is easy to be premature. As a result, the optimal solution obtained by GA is not the real global optimal solution. On the other hand, simulated annealing algorithm (SAA) has the ability of obtaining the real global optimal solution. Therefore, it is widely adopted to production management and engineering field, for example production scheduling, control engineering, and so on $[17,18]$. Mirsanei et al. studied the problem of sequencedependent setup times hybrid flow shop scheduling with parallel identical machines to minimize the makespan. They developed a novel simulated annealing algorithm to produce a reasonable manufacturing schedule within an acceptable computational time [19]. Precup et al. discussed the design of fuzzy control systems with a reduced parametric sensitivity using simulated-annealing algorithms and proved the FCS performance by the experimental results [20]. However, it takes a long time to obtain the global optimal solution of mass scale problem by SAA. Therefore, some researchers proposed hybrid genetic simulated annealing algorithms (HGSAAs) by combining the advantages of GA and SAA and proved that the performance of HGSAA is better than the basic GA and SAA $[21,22]$.

In this paper, we develop a replenishment and production model of ATO supply chain, which consists of an ATO manufacturer and multiple component suppliers, in order to study the mixed replenishment policy, JIT and $(Q, r)$, of the ATO manufacturer, as well as the component suppliers' production management policies. In addition, by combining the rapid global searching ability of genetic algorithm and the local searching ability of simulated annealing algorithm, we propose a hybrid genetic simulated annealing algorithm to search for the optimal solution of the model. Finally, we use a numeric example to illustrate the good performance of the HGSAA. This paper offers consultation and decision making support tools for ATO manufacturers and their components suppliers to make policies on production and replenishment policies.

The remainder of the paper is organized as follows. Section 2 is dedicated to the problem and assumptions. The model is developed in Section 3. We propose the HGSAA for the model in Section 4. An experiment is used to demonstrate the performance of the HGSAA in Section 5. Finally, conclusions are drawn in Section 6.

\section{The Problem and Assumptions}

An ATO supply chain consists of an ATO manufacturer and multiple component suppliers. The manufacturer adopts either $(Q, r)$ or JIT mode to replenish a kind of component from a component supplier. The process of the ATO manufacturer and its suppliers making their policies is as follows. Firstly, aiming at maximizing the total profit of the supply chain, the ATO manufacturer makes its replenishment policy for every kind of component, including replenishment mode and order quantity under $(Q, r)$ mode. Then, the component suppliers make their production policies according to the ATO manufacturer's replenishment policy in order to maximize their own profits.

The assumptions of this paper are as follows.

Assumption 1. The ATO manufacturer purchases $m$ kinds of components, which are not substitutable for each other, from $m$ component suppliers, and assembles these components into $n$ kinds of final products. The duration of assembly is short and negligible.

Assumption 2. The ATO manufacturer assembles products according to customers' orders after receiving them and immediately sends the products to customers after finishing the assembly. Therefore, the ATO manufacturer owns no product inventory but components inventory, which means no product holding cost. 
Assumption 3. The product demand is uncertain; therefore, there is a probability that some customers' demands are not satisfied. All these unsatisfied demands are lost.

Assumption 4. Arrange all the $m$ kinds of components according to the replenishment mode applied to them, that is, applying JIT replenishment to the first $k$ kinds of components and $(Q, r)$ replenishment to the last $m-k$ kinds of components.

Assumption 5. The component suppliers make their production management policies according to the ATO manufacturer's replenishment policy. If the ATO manufacturer replenishes components by JIT, component suppliers apply make-to-stock (MTS) to produce. If the ATO manufacturer replenishes components by $(Q, r)$, component suppliers apply make-to-order (MTO) to produce due to the lead time of replenishment.

The notations related to the ATO manufacturer in this paper are as follows.

$A_{i}$ : the annual expected demand of product $i, i=$ $1,2, \ldots, n$

$S_{i}$ : the selling price of product $i, i=1,2, \ldots, n$;

$b_{i}$ : the assembly cost of product $i, i=1,2, \ldots, n$;

$p_{i}$ : the probability of product $i$ being in shortage, $i=$ $1,2, \ldots, n$;

$k$ : the number of component kinds which are replenished by JIT, decision variable;

$D_{j}$ : the annual expected demand of component $j, j=$ $1,2, \ldots, m$;

$C_{j}$ : the purchase price of component $j, j=1,2, \ldots, m$;

$Q_{j}$ : the order quantity of component $j$ replenished by $(Q, r), j=k+1, k+2, \ldots, m$, decision variable;

$R_{j}$ : the replenishment cost per time of component $j$ replenished by $(Q, r), j=k+1, k+2, \ldots, m$;

$R_{j}^{\prime}$ : the replenishment cost per time of component $j$ replenished by JIT, $R_{j}^{\prime}<R_{j}, j=1,2, \ldots, k$;

$H$ : the holding cost per purchase price per time of all components;

$r_{j}$ : the reorder point of component $j$ replenished by $(Q, r), j=k+1, k+2, \ldots, m$, decision variable;

$x_{j}$ : the demand of component $j$ replenished by $(Q, r)$ in its lead time, $j=k+1, k+2, \ldots, m$.

The notations related to the component suppliers in this paper are as follows.

$P_{j}$ : the capability of the supplier producing component $j$ per time, $j=1,2, \ldots, m$;

$h_{j}$ : the holding cost per producing cost per time of component $j, j=1,2, \ldots, m$;

$s_{j}$ : the setup cost of component $j, j=1,2, \ldots, m$;

$c_{j}$ : the producing cost of component $j, j=1,2, \ldots, m$.

\section{The Model}

The ATO manufacturer makes its component replenishment policy for every component, including replenishment mode and replenishment quantity, aiming at maximizing the total profit of the whole supply chain. The sales revenue and costs consisting of profit function of the supply chain are as follows: (1) the sales revenue of the ATO manufacturer; (2) the ATO manufacturer's assembly cost; (3) the ATO manufacturer's total replenishment cost; (4) the ATO manufacturer's total holding cost of components replenished by $(Q, r)$; (5) the suppliers' total holding cost; (6) the suppliers' total setup cost; (7) the suppliers' total producing cost, including the cost of raw materials for components.

Before we give the sales revenue function of the ATO manufacturer, we analyze the probability of product $i$ and component $j$ being in shortage, $i=1,2, \ldots, n, j=$ $1,2, \ldots, m$. The ATO manufacturer adopts both $(Q, r)$ and JIT to replenish components. The components replenished by JIT will not be in shortage, while the components replenished by $(Q, r)$ may be in shortage during the replenishment lead time, which causes the final products to be in shortage. The expected shortage quantity of component $j$ in replenishment lead time is $L\left(r_{j}\right)=\int_{r_{j}}^{\infty}\left(x-r_{j}\right) g_{j}(x) d x, j=k+1, k+$ $2, \ldots, m$, where $g_{j}(x)$ is the demand distribution function of component $j$ in replenishment lead time. Then, we can get that the probability of component $j$ being in shortage is $L\left(r_{j}\right) / Q_{j}$. As the components are not substitutable for each other, the probability of final product $i$ being in shortage, $p_{i}$, is

$$
p_{i}=1-\prod_{j=1}^{m}\left[1-\delta_{i j} \frac{L\left(r_{j}\right)}{Q_{j}}\right], \quad i=1,2, \ldots, n,
$$

where

$$
\delta_{i j}= \begin{cases}1, & \text { the component } j \text { is used in product } i \\ \text { and replenished by }(Q, r)\end{cases}
$$

Then, we can get the sales revenue and costs of ATO supply chain as follows.

The sales revenue is

$$
\mathrm{TR}=\sum_{i=1}^{n}\left[S_{i} A_{i}\left(1-p_{i}\right)\right]
$$

The assembly cost of the ATO manufacturer is

$$
\mathrm{TC}_{a}=\sum_{i=1}^{n}\left[b_{i} A_{i}\left(1-p_{i}\right)\right]
$$

The component replenishment cost of the ATO manufacturer is

$$
\mathrm{TC}_{r}=\sum_{i=1}^{k} R_{j}^{\prime} D_{j}+\sum_{j=k+1}^{m} \frac{R_{j} D_{j}}{Q_{j}}
$$


The first part on the right side of (5) is the total replenishment cost of the $k$ components replenished by JIT; the second is the total replenishment cost of the $m-k$ components replenished by $(Q, r)$.

The expected net inventory level of component $j$ replenished by $(Q, r)$ just before the replenished components arrive is $r_{j}-x_{j}+L\left(r_{j}\right)$, and the expected inventory level just after the replenished components arrive is $Q_{j}+r_{j}-x_{j}+L\left(r_{j}\right)$. Therefore, the expected average inventory level is $r_{j}-x_{j}+L\left(r_{j}\right)+Q_{j} / 2$. Now, we can get the ATO manufacturer's total holding cost of the $m-k$ components replenished by $(Q, r)$ as follows:

$$
\mathrm{TC}_{a h}=H \sum_{j=k+1}^{m} C_{j}\left[\frac{Q_{j}}{2}+r_{j}-x_{j}+L\left(r_{j}\right)\right] \text {. }
$$

After the ATO manufacturer decides the replenishment mode of every component; the component suppliers make their production management policies. If the ATO manufacturer replenishes components by JIT, those component suppliers apply MTS to produce. If the ATO manufacturer replenishes components by $(Q, r)$, those component suppliers apply MTO to produce due to the lead time of replenishment. Then, we can get that the total holding cost and setup cost of the suppliers are as follows.

The suppliers' total holding cost is

$$
\mathrm{TC}_{v h}=\sum_{j=k+1}^{m} \frac{h_{j} c_{j} Q_{j} D_{j}}{2 P_{j}}+\sum_{j=1}^{k} \sqrt{\frac{s_{j} c_{j} h_{j}\left(P_{j}-D_{j}\right)}{2 P_{j}}}
$$

The suppliers' total setup cost is

$$
\mathrm{TC}_{s}=\sum_{j=k+1}^{m} \frac{D_{j} s_{j}}{Q_{j}}+\sum_{j=1}^{k} \sqrt{\frac{D_{j} c_{j} s_{j} h_{j}\left(P_{j}-D_{j}\right)}{2 P_{j}}}
$$

The first parts on the right side of (7) and (8) are individually the holding costs and setup costs for the components replenished by $(Q, r)$, and the second parts are individually the holding costs and setup costs for the components replenished by JIT.

The suppliers' total producing cost is

$$
\mathrm{TC}_{m}=\sum_{j=1}^{m} c_{j} D_{j}
$$

Then, we can get the total profit of the ATO supply chain as

$$
\pi=\mathrm{TR}-\mathrm{TC}_{a}-\mathrm{TC}_{r}-\mathrm{TC}_{a h}-\mathrm{TC}_{v h}-\mathrm{TC}_{s}-\mathrm{TC}_{m}
$$

The target of the ATO manufacturer's decision making is maximizing the total profit of the ATO supply chain by deciding which $k$ kinds of components are replenished by JIT and which $m-k$ kinds of components are replenished by $(Q, r)$, as well as the replenishment quantities and the reorder points of component $j$ replenished by $(Q, r)$. Therefore, the optimal model of ATO supply chain making its mixed replenishment policies is as follows:

$$
\begin{array}{ll}
\max _{k, Q_{j}, r_{j}} & \pi . \\
\text { s.t. } & m \geq k \geq 0, \\
& D_{j} \geq Q_{j} \geq 0, \\
& D_{j} \geq r_{j} \geq 0,
\end{array}
$$

where $j=k+1, k+2, \ldots, m$.

\section{The Proposed Hybrid Genetic Simulated Annealing Algorithm}

This paper proposes to incorporate the strengths of a genetic algorithm into a simulated annealing algorithm. GA is developed to rapidly search for an optimal or near-optimal solution among the solution space, and then SAA is utilized to seek a better one on the basis of that solution. Therefore, the weakness of the prematurity of GA and the time-consuming nature of SAA is overcome, and the global optimal solution is obtained rapidly.

HGSAAs have been increasingly used to obtain the optimal solution of combinatorial optimization problems. Elhaddad and Sallabi proposed new operations and techniques to improve the performance of GA and then combined the improved GA with SAA for implementing a hybrid algorithm (HGSAA) to solve Traveling Salesman Problem (TSP) [23]. Wang et al. studied the multivehicle and multicargo loading problem under limited loading capacity and used hybrid genetic simulated annealing algorithm to get the optimization solution [24]. Moussi et al. used three HGSAAs to solve the storage container problem in port [25]. Furthermore, Li et al. proposed an effective hybrid genetic simulated annealing algorithm to obtain the optimal solution for the locationinventory-routing problem considering returns under esupply chain environment [26].

However, HGSAAs have been rarely used to solve the optimization problem of mixed replenishment policy for the ATO supply chain. As we discussed above, the complexity of this problem is $2^{n}$ and a little error may cause an ATO manufacturer a huge profit loss. Therefore, we utilize the particularities of HGSAA, which are converging more rapidly and obtaining the solution more accurately, to solve the mixed replenishment policy problem.

\subsection{The HGSAA for the Mixed Replenishment Policy}

4.1.1. Encoding. We use binary encoding in the HGSAA. If a component is replenished by JIT mode, the code of the component will be set as 0 ; if the component is replenished by $(Q, r)$ mode, the code will be set as 1 .

4.1.2. Fitness Function. Since the objective function is maximizing the ATO supply chain's total profit, and the fitness function values must be nonnegative, so we define the fitness function as $\operatorname{Fit}\left(k, Q_{j}, r_{j}\right)=\pi\left(k, Q_{j}, r_{j}\right)+\overline{\mathrm{TC}}$, where 
$\left(k, Q_{j}, r_{j}\right)$ represents a mixed components replenishment policy, $\pi\left(k, Q_{j}, r_{j}\right)$ represents the total profit of the ATO supply chain under the $\left(k, Q_{j}, r_{j}\right)$ replenishment policy, $\overline{\mathrm{TC}}$ represents the upper limit of the supply chain's total cost, and $\overline{\mathrm{TC}}=\sum_{i=1}^{n}\left(b_{i} A_{i}\right)+\sum_{j=1}^{m}\left(c_{j} D_{j}\right)+\sum_{j=1}^{m}\left(H D_{j} C_{j} / 2\right)+$ $\sum_{j=1}^{m}\left(h_{j} D_{j} c_{j} / 2\right)+\sum_{j=1}^{m}\left(R_{j}^{\prime} D_{j}\right)+\sum_{j=1}^{m}\left(s_{j} D_{j}\right) \cdot \sum_{j=1}^{m}\left(b_{i} A_{i}\right)$ is the upper limit of the ATO manufacturer's assembly cost, $\sum_{j=1}^{m}\left(C_{j} D_{j}\right)$ is the upper limit of the suppliers' total producing cost, $\sum_{j=1}^{m}\left(H D_{j} C_{j} / 2\right)+\sum_{j=1}^{m}\left(h_{j} D_{j} c_{j} / 2\right)$ are the upper limit of the ATO supply chain's holding cost, $\sum_{j=1}^{m}\left(R_{j}^{\prime} D_{j}\right)$ is the upper limit of the ATO manufacturer's replenishment cost, and $\sum_{j=1}^{m}\left(s_{j} D_{j}\right)$ is the upper limit of the supplier's total setup cost. Therefore, $\overline{\mathrm{TC}}$ is a fixed constant used to guarantee the fitness function values to be nonnegative, which has no impact on the result of the algorithm.

4.1.3. Selection. The selection method in the algorithm is roulette-wheel-selection. The greater the individual fitness value is, the greater probability that the individual is selected. The process of selection is as follows. Firstly, calculate the selected probability $P_{i}$ of the individual $i, P_{i}=$ Fit $_{i} / \sum_{l=1}^{S}$ Fit $_{l}$, where $S$ is the population size. Then, generate a random number $r$ which belongs to [0,1]. Finally, the individual $i$ is selected, if $\sum_{l=0}^{i-1} P_{l} \leq r \leq \sum_{l=0}^{i} P_{l}$, where $P_{0}=0$.

4.1.4. Crossover and Mutation. In this paper, we use sequencing crossover to exchange the sequence of the operations in the parent chromosomes and assignment mutation to change the assignment of a single operation in a single parent. The crossover probability $p_{c}=0.8$; the mutation probability $p_{m}=$ 0.05 .

4.1.5. Simulated Annealing. Simulated annealing is based on the metropolis acceptance criterion, which models how a thermodynamic system moves from the current state to a candidate state, in which the energy content is being minimized.

In the genetic simulated annealing algorithm, only one of the parent individuals $p$ and the child individuals $c$ can be accepted to the next generation; simulated annealing is used to determine which one is accepted; the acceptance probability $P$ is shown as follow:

$$
P= \begin{cases}1, & \pi_{c}>\pi_{p} \\ \exp \left(\frac{\pi_{c}-\pi_{p}}{t}\right), & \pi_{c} \leq \pi_{p}\end{cases}
$$

where $\pi_{p}$ and $\pi_{c}$ are the fitness values of individual $p$ and $c$, and $t$ is the current temperature.

4.1.6. Termination or Convergence Criterion. If the algorithm satisfies the following criteria, then terminate and output the best chromosome, that is, the optimal mixed replenishment policy. (i) The fitness value has no significant change after successive iterations, which means the current policy is the optimal mixed replenishment policy.

(ii) The number of iterations reaches the set value.

4.2. The Steps of the HGSAA. The steps of the HGSAA are as follows.

Step 1 (initialization). get the encoding length according to the number of components; set the population size $(S)$, the crossover probability $\left(p_{c}\right)$, the mutation probability $\left(p_{m}\right)$, the iteration number of the genetic algorithm $(I)$, the start temperature $\left(T_{0}\right)$, the stop temperature $\left(T_{e}\right)$, andthe annealing rate $(\mu)$; then generate the initial population.

Step 2. Evaluate the fitness function for the current population (parent population).

Step 3. Make selection, crossover, and mutation operation on the parent population to generate an offspring population.

Step 4. Make simulated annealing operation on the parent population and the offspring population to generate a new population for next iteration; update the temperature.

Step 5. If the termination or convergence criterion is satisfied, terminate the process and output the best chromosome, together with the corresponding policy. Otherwise, go to Step 2.

The proposed hybrid genetic simulated annealing algorithm for the mixed replenishment policy is illustrated in Figure 1.

\section{Experimental Analysis}

5.1. The Solutions of the HGSAA. In an ATO supply chain, an ATO manufacturer replenishes 20 kinds of components (labeled as $p_{1}$ to $p_{20}$ ) from 20 suppliers (correspondingly labeled as $s_{1}$ to $s_{20}$ ) and assembles these components into 2 different products, namely, product 1 and product 2 . The parameters of these products are as follows. The annual expected demands, selling prices, assembly costs, and holding cost per purchase price per time are individually $A_{1}=300$ units per year, $A_{2}=400$ units per year, $S_{1}=6500$ per unit, $S_{2}=7500$ per unit, $b_{1}=100$ per unit, $b_{2}=120$ per unit, and $H=0.2$ per purchase price per year. The demands of all components are independent and follow a normal distribution. Other parameters of the components are shown in Tables 1 and 2.

The parameters in the HGSAA are set as follows: the population size $(S)=100$; the crossover probability $\left(p_{c}\right)=$ 0.8 ; the mutation probability $\left(p_{m}\right)=0.05$; the iteration number of the genetic algorithm $(I)=10$; the start temperature $\left(T_{0}\right)=100$; the stop temperature $\left(T_{e}\right)=1$; the annealing rate $(\mu)=0.95$.

In order to testify the performance of the HGSAA of this paper, we apply it to search for the optimal mixed replenishment policies under three conditions. Condition 1: 
TABLE 1: The parameters of the ATO manufacturer.

\begin{tabular}{|c|c|c|c|c|c|c|c|c|}
\hline Component & $\begin{array}{l}\text { Quantity } \\
\text { needed by } \\
\text { Product } 1 \\
\text { (units) }\end{array}$ & $\begin{array}{l}\text { Quantity } \\
\text { needed by } \\
\text { Product } 2 \\
\text { (units) }\end{array}$ & $\begin{array}{c}\text { Annual } \\
\text { expected } \\
\text { demand (units } \\
\text { per year) }\end{array}$ & $\begin{array}{l}\text { Purchase } \\
\text { price } \\
\text { (per unit) }\end{array}$ & $\begin{array}{l}\text { Demand in } \\
\text { lead time } \\
\text { (units) }\end{array}$ & $\begin{array}{c}\text { Standard } \\
\text { deviation of } \\
\text { demand }\end{array}$ & $\begin{array}{l}\text { Replenishment } \\
\text { cost of }(Q, r) \\
\quad \text { (per time) }\end{array}$ & $\begin{array}{c}\text { Replenishment } \\
\text { cost of JIT (per } \\
\text { unit) }\end{array}$ \\
\hline$p_{1}$ & 1 & 2 & 1100 & 100 & 25 & 14 & 600 & 8 \\
\hline$p_{2}$ & 3 & 1 & 1300 & 150 & 53 & 22 & 750 & 9 \\
\hline$p_{3}$ & 1 & 3 & 1500 & 120 & 12 & 6 & 800 & 10.5 \\
\hline$p_{4}$ & 1 & 3 & 1500 & 130 & 33 & 16 & 720 & 8.8 \\
\hline$p_{5}$ & 2 & 2 & 1400 & 95 & 20 & 10 & 650 & 8.1 \\
\hline$p_{6}$ & 2 & 1 & 1000 & 90 & 17 & 8 & 680 & 8.3 \\
\hline$p_{7}$ & 1 & 3 & 1500 & 110 & 45 & 20 & 850 & 11.5 \\
\hline$p_{8}$ & 1 & 2 & 1100 & 85 & 39 & 18 & 780 & 9.3 \\
\hline$p_{9}$ & 2 & 1 & 1000 & 80 & 60 & 28 & 820 & 11.0 \\
\hline$p_{10}$ & 1 & 3 & 1500 & 140 & 48 & 24 & 700 & 8.5 \\
\hline$p_{11}$ & 4 & 2 & 2000 & 150 & 75 & 36 & 500 & 7.0 \\
\hline$p_{12}$ & 2 & 2 & 1400 & 200 & 43 & 21 & 900 & 12.0 \\
\hline$p_{13}$ & 1 & 1 & 700 & 180 & 65 & 32 & 1000 & 13.0 \\
\hline$p_{14}$ & 2 & 3 & 1800 & 160 & 37 & 20 & 1100 & 14.0 \\
\hline$p_{15}$ & 3 & 4 & 2500 & 170 & 29 & 12 & 950 & 12.5 \\
\hline$p_{16}$ & 1 & 1 & 700 & 190 & 19 & 8 & 550 & 7.5 \\
\hline$p_{17}$ & 1 & 1 & 700 & 185 & 73 & 34 & 880 & 11.8 \\
\hline$p_{18}$ & 3 & 2 & 1700 & 210 & 46 & 18 & 920 & 12.2 \\
\hline$p_{19}$ & 3 & 3 & 1700 & 135 & 58 & 26 & 1050 & 13.5 \\
\hline$p_{20}$ & 2 & 3 & 1800 & 175 & 69 & 33 & 980 & 12.8 \\
\hline
\end{tabular}

TABLE 2: The parameters of the suppliers.

\begin{tabular}{|c|c|c|c|c|}
\hline Supplier & $\begin{array}{l}\text { Holding cost (per } \\
\text { producing cost per } \\
\text { time) }\end{array}$ & $\begin{array}{l}\text { Setup cost } \\
\text { (per time) }\end{array}$ & $\begin{array}{l}\text { Producing cost } \\
\quad \text { (per time) }\end{array}$ & $\begin{array}{l}\text { Producing capability } \\
\quad \text { (units per year) }\end{array}$ \\
\hline$s_{1}$ & 0.21 & 500 & 70 & 2000 \\
\hline$s_{2}$ & 0.22 & 700 & 115 & 2200 \\
\hline$s_{3}$ & 0.21 & 750 & 100 & 3000 \\
\hline$s_{4}$ & 0.20 & 740 & 90 & 2900 \\
\hline$s_{5}$ & 0.23 & 730 & 95 & 2700 \\
\hline$s_{6}$ & 0.21 & 450 & 60 & 1800 \\
\hline$s_{7}$ & 0.22 & 740 & 110 & 2800 \\
\hline$s_{8}$ & 0.20 & 480 & 65 & 1900 \\
\hline$s_{9}$ & 0.23 & 460 & 68 & 1850 \\
\hline$s_{10}$ & 0.24 & 760 & 80 & 3100 \\
\hline$s_{11}$ & 0.25 & 600 & 77 & 2300 \\
\hline$s_{12}$ & 0.20 & 800 & 105 & 3500 \\
\hline$s_{13}$ & 0.23 & 900 & 84 & 4000 \\
\hline$s_{14}$ & 0.26 & 860 & 66 & 3800 \\
\hline$s_{15}$ & 0.21 & 770 & 73 & 3200 \\
\hline$s_{16}$ & 0.23 & 420 & 82 & 1600 \\
\hline$s_{17}$ & 0.24 & 710 & 98 & 2500 \\
\hline$s_{18}$ & 0.22 & 880 & 120 & 3900 \\
\hline$s_{19}$ & 0.22 & 720 & 88 & 2600 \\
\hline$s_{20}$ & 0.21 & 830 & 62 & 3600 \\
\hline
\end{tabular}


TABLE 3: The results.

\begin{tabular}{|c|c|c|c|c|c|c|}
\hline $\begin{array}{l}\text { Number of } \\
\text { components }\end{array}$ & $\begin{array}{l}\text { The best } \\
\text { chromosome }\end{array}$ & Replenishment policy & $\begin{array}{l}\text { Complexity of } \\
\text { the problem }\end{array}$ & $\begin{array}{l}\text { The final } \\
\text { number of } \\
\text { iterations }\end{array}$ & $\begin{array}{c}\text { The optimal } \\
\text { solution of the } \\
\text { HGSAA }\end{array}$ & $\begin{array}{c}\text { The real optimal } \\
\text { solution }\end{array}$ \\
\hline 10 & 1011111111 & $\begin{array}{l}p_{2} \text { is replenished by } \\
\text { JIT; others are } \\
\text { replenished by }(Q, r)\end{array}$ & $2^{10}$ & 20 & $5.7562 e+05$ & $5.7562 e+05$ \\
\hline 15 & 101111111101011 & $\begin{array}{c}p_{2}, p_{11}, \text { and } p_{13} \text { are } \\
\text { replenished by JIT; } \\
\text { others are replenished } \\
\text { by }(Q, r)\end{array}$ & $2^{15}$ & 50 & $1.1448 e+06$ & $1.1448 e+06$ \\
\hline 20 & 10111111110101100111 & $\begin{array}{c}p_{2}, p_{11}, \text { and } p_{13} \text { and } \\
p_{16} \text { are replenished by } \\
\text { JIT; others are } \\
\text { replenished by }(Q, r)\end{array}$ & $2^{20}$ & 100 & $2.2140 e+06$ & $2.2140 e+06$ \\
\hline
\end{tabular}

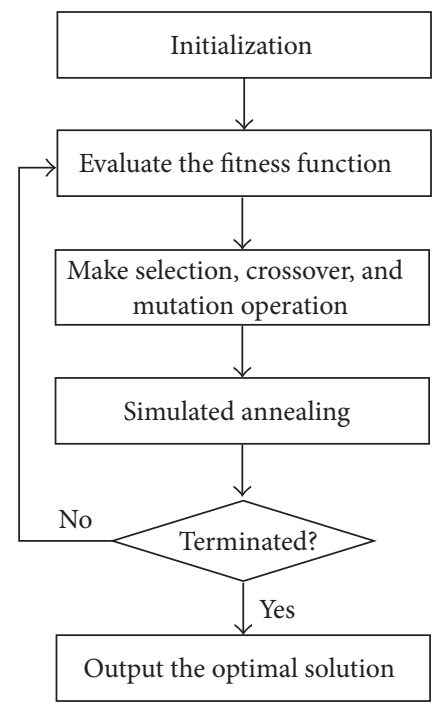

FIGURE 1: The hybrid genetic simulated annealing algorithm.

assemble components $p_{1}-p_{10}$ (10 kinds of components) into product 1 and product 2 . Condition 2: assemble components $p_{1}-p_{15}$ (15 kinds of components) into product 1 and product 2. Condition 3: assemble components $p_{1}-p_{20}$ (20 kinds of components) into product 1 and product 2 . The results of the HGSAA under these three conditions are as in Table 3.

From Table 3, we can get that under the condition of 10 , 15 , and 20 kinds of components, the complexities of the mixed replenishment policy for the ATO supply chain are $2^{10}, 2^{15}$, and $2^{20}$, respectively. Though it just takes 20,50 , and 100 iterations to get the optimal solutions by HGSAA, the optimal solutions of the HGSAA are the real optimal ones. Thus it can be proved that the HGSAA is an effective algorithm for solving the optimization problem of mixed replenishment policy for the ATO supply chain.

5.2. Comparison of the HGSAA and GA. Now, we compare the HGSAA with GA to show the better performance of the HGSAA for solving the problem of mixed replenishment policy for ATO supply chain. Each algorithm is independently

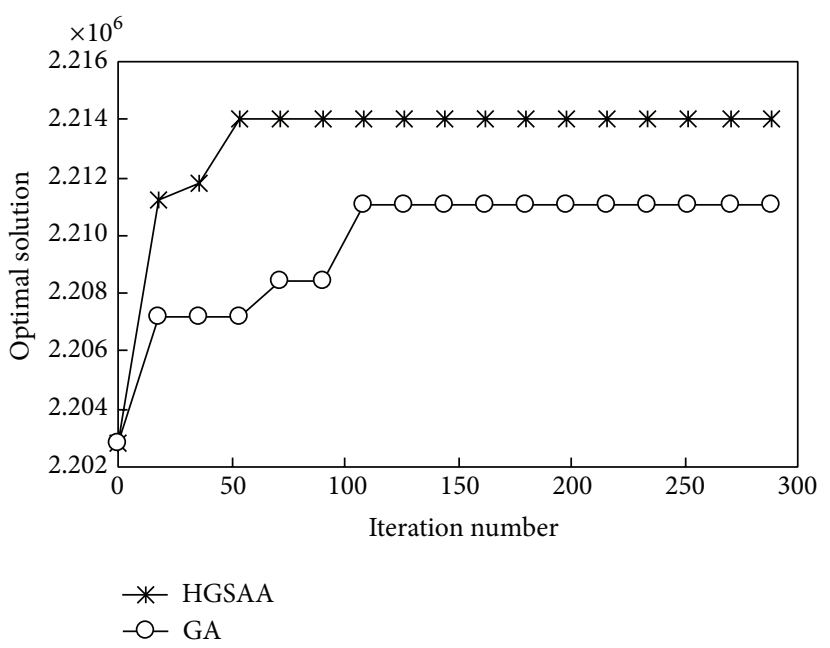

FIgURE 2: Comparison of the HGSAA and GA.

repeated 10 times, 20 times, 50 times, and 100 times, where dimension is 20 . If the final searching quality is within $10^{-4}$ of the optimal value, the run is called a success run and its iteration number will be stored. Furthermore, Wilcoxon test $[27,28]$ is used to validate the statistical significance of the results.

Table 4 shows the means and standard deviations of the HGSAA and GA. Figure 2 shows the performance of the HGSAA and GA for solving the problem of mixed replenishment policy for ATO supply chain.

From Table 4, it can be found that the means of the HGSAA are closer to the theoretical optima, and the standard deviations of HGSAA are smaller than those of GA. Furthermore, Wilcoxon test shows the results of comparison are all statistically significant.

It can then be seen from Figure 2 that the curve of objective values of the HGSAA ascends faster than that of GA and the searching quality of the HGSAA is better than GA.

We use two indices named "number of successful hits" and "average valid iteration number" to analyse the robustness of the HGSAA and GA, while "number of successful hits" 
TABLE 4: Means and standard deviations of HGSAA and GA.

\begin{tabular}{lccccc}
\hline \multirow{2}{*}{ Running times } & \multicolumn{2}{c}{ HGSAA } & \multicolumn{2}{c}{ GA } & Wilcoxon test \\
& Mean & Standard deviation & $2.2131 e+06$ & 1273.9000 & Standard deviation \\
\hline 10 & $2.2140 e+06$ & 87.0550 & $2.2137 e+06$ & 509.3638 & 0.0910 \\
20 & $2.2140 e+06$ & $4.7776 e-10$ & $2.2134 e+06$ & 812.6267 & 0.0042 \\
50 & $2.2140 e+06$ & 38.9322 & $2.2134 e+06$ & 926.2284 & 0.00000 \\
100 & $2.2140 e+06$ & 27.5292 & & \\
\hline
\end{tabular}

TABLE 5: Means and standard deviations of HGSAA and GA.

\begin{tabular}{|c|c|c|c|c|}
\hline \multirow{2}{*}{ Running times } & \multicolumn{2}{|c|}{ HGSAA } & \multicolumn{2}{|c|}{ GA } \\
\hline & $\begin{array}{c}\text { Number of } \\
\text { successful hits }\end{array}$ & $\begin{array}{l}\text { Average valid } \\
\text { iteration number }\end{array}$ & $\begin{array}{c}\text { Number of } \\
\text { successful hits }\end{array}$ & $\begin{array}{c}\text { Average valid } \\
\text { iteration number }\end{array}$ \\
\hline 10 & 9 & 102 & 6 & 185 \\
\hline 20 & 20 & 87 & 13 & 133 \\
\hline 50 & 49 & 80 & 30 & 160 \\
\hline 100 & 99 & 82 & 56 & 177 \\
\hline
\end{tabular}

represents the number of successful runs among 10 runs, 20 runs, 50 runs, and 100 runs in which the optimal solution was obtained; "average valid iteration number" represents the average number of iterations for success runs among 10 runs, 20 runs, 50 runs, and 100 runs. The results of robustness analysis are shown in Table 5.

Table 5 shows that the HGSAA can find global optima with higher "number of successful hits" than GA, and for those valid runs, the HGSAA requires smaller "average valid iteration number" than GA.

From the above comparison, we can make the conclusion that the HGSAA is more effective and reliable than GA for solving the optimization problem of mixed replenishment policy for the ATO supply chain.

\section{Conclusions}

In this paper, we developed a replenishment and production model of ATO supply chain to study the mixed replenishment policy (i.e., JIT and $(Q, r)$ mixed) of the ATO manufacturer, as well as the component suppliers' production management policies. In addition, through combining the rapid global searching ability of GA and the local searching ability of SAA, we proposed a HGSAA to search for the optimal solution of the model. Finally, an experiment was given to demonstrate the good performance of the HGSAA. This paper also offers consultation and decision making support tools for ATO manufacturers and their component suppliers to make policies on production and replenishment. It is proved that the HGSAA overcomes the prematurity of GA and the time-consuming nature of SAA; it has the ability of converging on the global optimal solution rapidly and is an effective algorithm for solving the optimization problem of mixed replenishment policy for the ATO supply chain.

\section{Conflict of Interests}

The authors declare that there is no conflict of interests regarding the publication of this paper.

\section{Acknowledgments}

The corresponding author of this paper is Bo Huang. This work is supported by the National Natural Science Foundation of China (no. 71102178), Social Science Foundation of Ministry of Education of China (Grant no. 11YJC630070), The Basic and Frontier Research Projects of Chongqing (cstc2013jcyjA0998), and the Fundamental Research Funds for the Central Universities (Grant no. CDJSK100201).

\section{References}

[1] Y. Y. Li and B. Huang, "Product selection and components replenishment model of ATO manufacturer under heterogeneous demand," Journal of Applied Mathematics, vol. 2013, Article ID 714715, 8 pages, 2013.

[2] Y.-C. Tsao, "Replenishment policies considering trade credit and logistics risk," Scientia Iranica, vol. 18, no. 3, pp. 753-758, 2011.

[3] S. I. Satoglu and I. E. Sahin, "Design of a just-in-time periodic material supply system for the assembly lines and an application in electronics industry," International Journal of Advanced Manufacturing Technology, vol. 65, no. 1-4, pp. 319-332, 2013.

[4] M. Bakker, J. Riezebos, and R. H. Teunter, "Review of inventory systems with deterioration since 2001," European Journal of Operational Research, vol. 221, no. 2, pp. 275-284, 2012.

[5] R. J. Tersine and J. G. Wacker, "Customer-aligned inventory strategies: agility maxims," International Journal of Agile Management Systems, vol. 2, no. 2, pp. 114-120, 2000. 
[6] Y. Akçay and S. H. Xu, "Joint inventory replenishment and component allocation optimization in an assemble-to-order system," Management Science, vol. 50, no. 1, pp. 99-116, 2004.

[7] Y. Lu and J.-S. Song, "Order-based cost optimization in assemble-to-order systems," Operations Research, vol. 53, no. 1, pp. 151-169, 2005.

[8] S. Benjaafar and M. Elhafsi, "Production and inventory control of a single product assemble-to-order system with multiple customer classes," Management Science, vol. 52, no. 12, pp. 18961912, 2006.

[9] J.-S. Yang and J. C.-H. Pan, "Just-in-time purchasing: an integrated inventory model involving deterministic variable lead time and quality improvement investment," International Journal of Production Research, vol. 42, no. 5, pp. 853-863, 2004.

[10] M. Wu and S. P. Low, "Modeling just-in-time purchasing in the ready mixed concrete industry," International Journal of Production Economics, vol. 107, no. 1, pp. 190-201, 2007.

[11] B. Dan, Y.-Y. Li, and B. Huang, "Mixed component replenishment policies for ATO supply chain under mass customization circumstance," Computer Integrated Manufacturing Systems, vol. 17, no. 6, pp. 1271-1278, 2011.

[12] J. M. Betts and R. B. Johnston, "Just-in-time component replenishment decisions for assemble-to-order manufacturing under capital constraint and stochastic demand," International Journal of Production Economics, vol. 95, no. 1, pp. 51-70, 2005.

[13] X. Wang, Y. Wang, and H. Zhu, "Energy-efficient multi-job scheduling model for cloud computing and its genetic algorithm," Mathematical Problems in Engineering, vol. 2012, Article ID 589243, 16 pages, 2012.

[14] Z. Ursani, D. Essam, D. Cornforth, and R. Stocker, "Localized genetic algorithm for vehicle routing problem with time windows," Applied Soft Computing, vol. 11, no. 8, pp. 5375-5390, 2011.

[15] A. Jalilvand-Nejad and P. Fattahi, "A mathematical model and genetic algorithm to cyclic flexible job shop scheduling problem," Journal of Intelligent Manufacturing, vol. 23, no. 10, pp. 1-14, 2013.

[16] A. S. Tasan and M. Gen, "A genetic algorithm based approach to vehicle routing problem with simultaneous pick-up and deliveries," Computers and Industrial Engineering, vol. 62, no. 3, pp. 755-761, 2012.

[17] B. Naderi, R. Tavakkoli-Moghaddam, and M. Khalili, "Electromagnetism-like mechanism and simulated annealing algorithms for flowshop scheduling problems minimizing the total weighted tardiness and makespan," Knowledge-Based Systems, vol. 23, no. 2, pp. 77-85, 2010.

[18] Q. Xu, J. Mao, and Z. H. Jin, "Simulated annealing-based ant colony algorithm for tugboat scheduling optimization," Mathematical Problems in Engineering, vol. 2012, Article ID 246978, 22 pages, 2012.

[19] H. S. Mirsanei, M. Zandieh, M. J. Moayed, and M. R. Khabbazi, "A simulated annealing algorithm approach to hybrid flow shop scheduling with sequence-dependent setup times," Journal of Intelligent Manufacturing, vol. 22, no. 6, pp. 965-978, 2011.

[20] R.-E. Precup, R.-C. David, E. M. Petriu, S. Preitl, and M.B. Radac, "Fuzzy control systems with reduced parametric sensitivity based on simulated annealing," IEEE Transactions on Industrial Electronics, vol. 59, no. 8, pp. 3049-3061, 2012.

[21] M. Dai, D. B. Tang, A. Giret, M. A. Salido, and W. D. Li, "Energy-efficient scheduling for a flexible flow shop using an improved genetic-simulated annealing algorithm," Robotics and Computer-Integrated Manufacturing, vol. 29, no. 5, pp. 418-429, 2013.
[22] A. H. Gandomi, A. H. Alavi, D. Mohammadzadeh Shadmehri, and M. G. Sahab, "An empirical model for shear capacity of RC deep beams using genetic-simulated annealing," Archives of Civil and Mechanical Engineering, vol. 13, no. 3, pp. 354-369, 2013.

[23] Y. Elhaddad and O. Sallabi, "A new hybrid genetic and simulated annealing algorithm to solve the traveling salesman problem," in Proceedings of the World Congress on Engineering, vol. 1, pp. 11-14, July 2010.

[24] X. Wang, J. Sun, and C. Ren, "Study on hybrid genetic simulated annealing algorithm for multi-vehicle and multi-cargo loading problem," Advanced Materials Research, vol. 171-172, pp. 167-170, 2011.

[25] R. Moussi, N. F. Ndiaye, and A. Yassine, "Hybrid Genetic Simulated Annealing Algorithm (HGSAA) to solve storage container problem in port," in Intelligent Information and Database Systems, J. S. Pan, S. M. Chen, and N. T. Nguyen, Eds., vol. 7197 of Lecture Notes in Computer Science, pp. 301-310, Springer, Berlin, Germany, 2012.

[26] Y. Li, H. Guo, L. Wang, and J. Fu, "A Hybrid Genetic-Simulated Annealing Algorithm for the location- inventory-routing problem considering returns under E-Supply chain environment," The Scientific World Journal, vol. 2013, Article ID 125893, 10 pages, 2013.

[27] F. Wilcoxon, "Individual comparisons by ranking methods," Biometrics, vol. 1, no. 6, pp. 80-83, 1945.

[28] S. García, D. Molina, M. Lozano, and F. Herrera, "A study on the use of non-parametric tests for analyzing the evolutionary algorithms' behaviour: a case study on the CEC'2005 Special Session on Real Parameter Optimization," Journal of Heuristics, vol. 15, no. 6, pp. 617-644, 2009. 


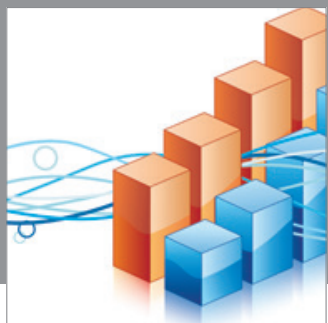

Advances in

Operations Research

mansans

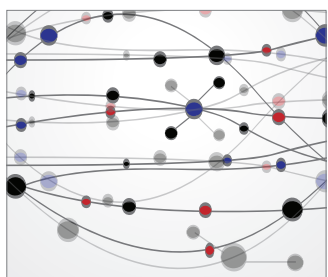

The Scientific World Journal
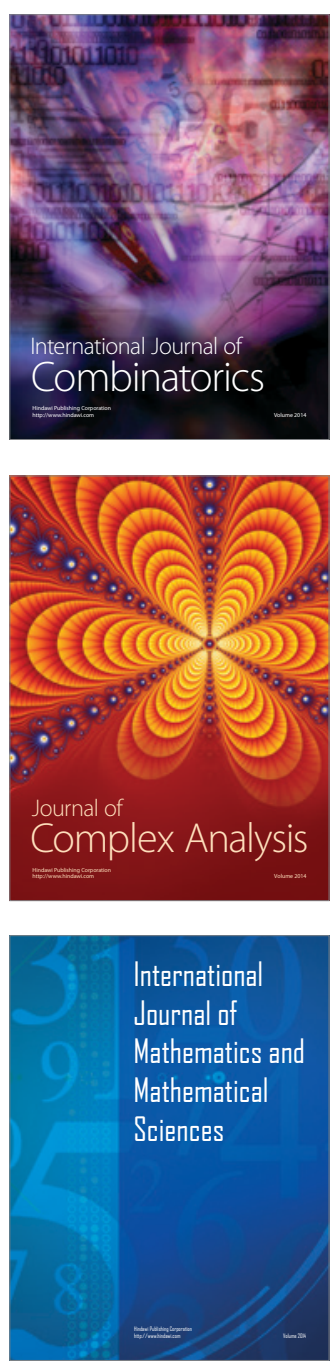
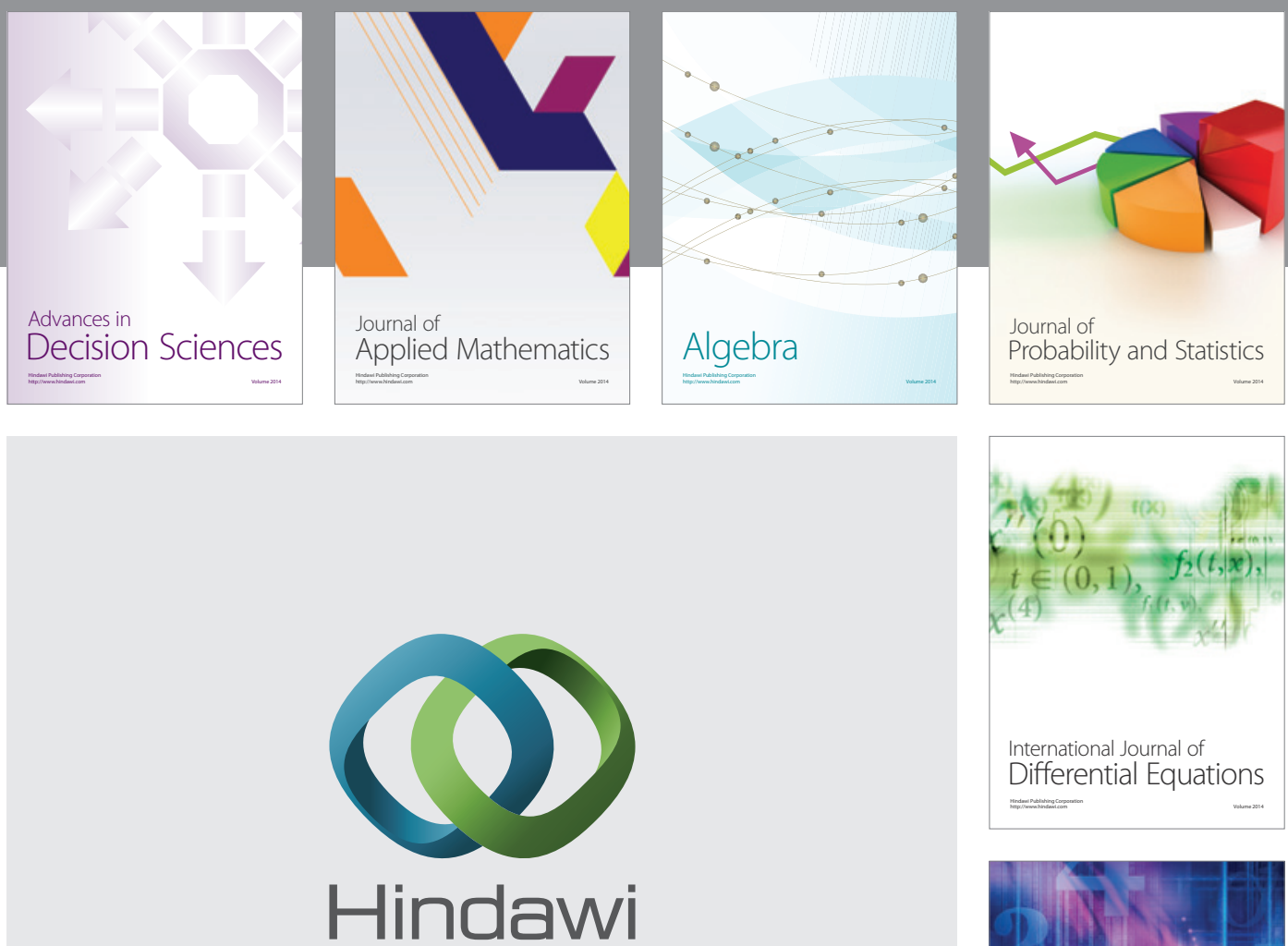

Submit your manuscripts at http://www.hindawi.com
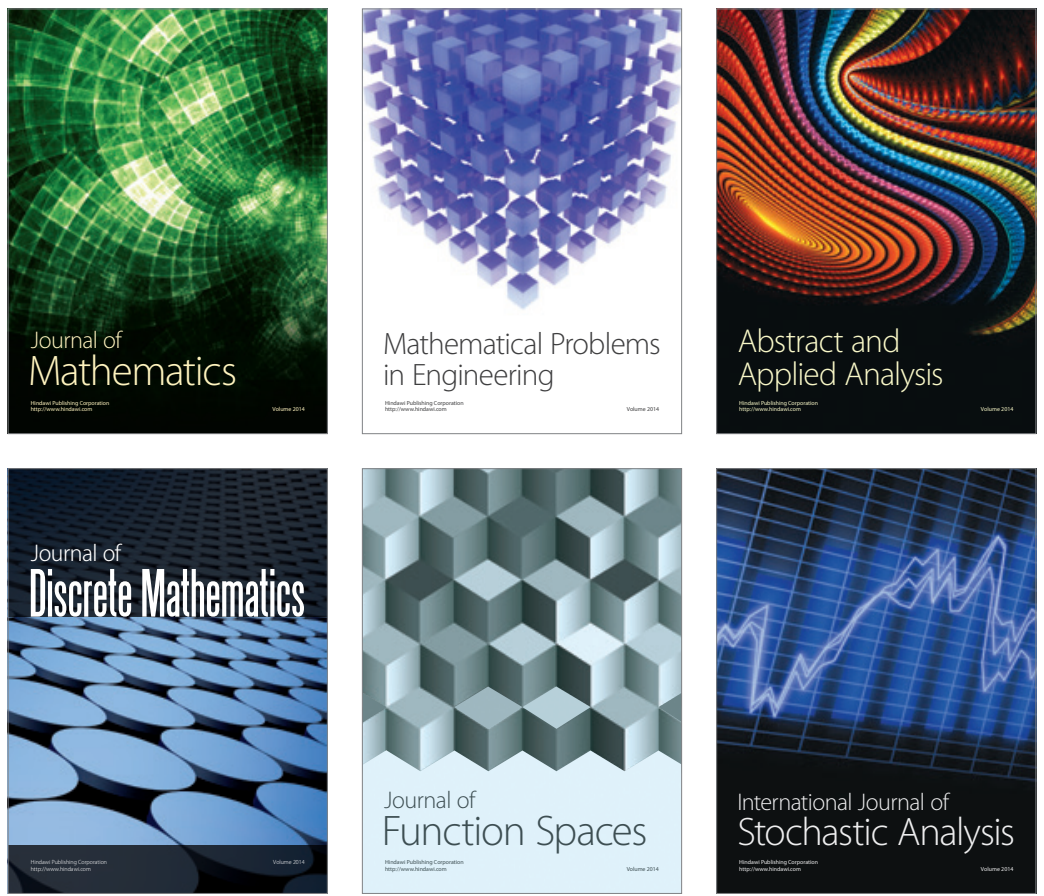

Journal of

Function Spaces

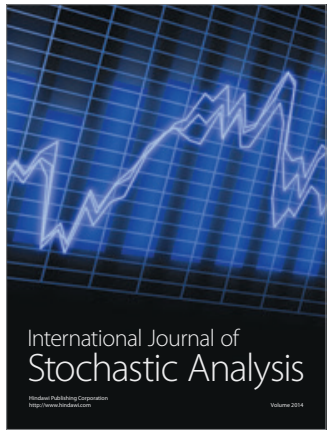

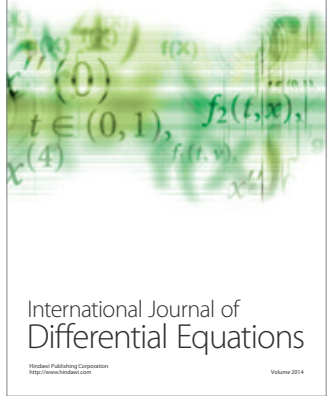
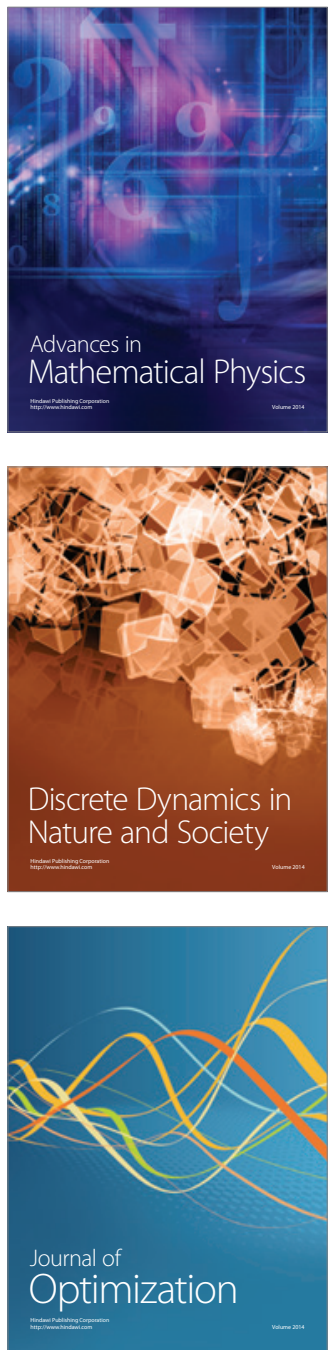